\title{
A New Surgical Technique of Combination Retroperitoneal with Transperitoneal Laparoscopic Nephroureterectomy in a Single Position and Comparative Outcomes
}

This article was published in the following Dove Press journal:

Cancer Management and Research

\author{
Liming Song ${ }^{1}, *$ \\ Wenkuan Wang ${ }^{2} * *$ \\ Qinxin Zhao ${ }^{3, *}$ \\ Yuhong Wen ${ }^{4}$ \\ Xiaoguang Zhou' \\ Hu Han' \\ Xiaodong Zhang' \\ 'Department of Urology, Beijing \\ Chaoyang Hospital, Capital Medical \\ University, Beijing, People's Republic of \\ China; ${ }^{2}$ Department of Urology, Beijing \\ Haidian Hospital/Haidian Hospital of \\ Beijing University Third Hospital, Beijing, \\ People's Republic of China; ${ }^{3}$ Department \\ of Urology, National Cancer Center/ \\ National Clinical Research Center for \\ Cancer/Cancer Hospital, Chinese \\ Academy of Medical Sciences and Peking \\ Union Medical College, Beijing, People's \\ Republic of China; ${ }^{4}$ Department of \\ Urology, Huhehaote First Hospital, Inner \\ Mongolia, People's Republic of China
}

*These authors contributed equally to this work
Correspondence: Liming Song Department of Urology, Beijing Chaoyang Hospital, Capital Medical University, Beijing 100020, People's Republic of China Email bjslm2020@I63.com
Background: The traditional surgical treatment for upper urinary tract urothelial carcinoma (UTUC) is time-consuming owing to changing the surgical position and larger surgical trauma because of open surgery in handling the distal ureter. Therefore, we created a new surgical technique of combination retroperitoneal with transperitoneal (CRT) laparoscopic nephroureterectomy (LNU) in a single position and here report our early outcomes.

Methods: From January 2017 to December 2019, a total of 106 patients underwent LNU by a single surgeon at our department, of whom 50 patients underwent standard technique and 56 patients underwent CRT technique. Relevant clinical data were collected including each patient's characteristics, surgical outcomes, and follow-up results. A comparative analysis between standard LNU cases and CRT LNU cases was performed.

Results: LNU was performed successfully on all 106 patients. There was no significant difference in patients' characteristics. Compared to the standard group, patients in the CRT group had shorter operative time $(P=0.001)$, less estimated blood loss (EBL) $(P<0.001)$, lower visual analogue scale (VAS) pain score $(P=0.020)$ and less scarring $(P=0.013)$. The median time of surgical drain stay decreased from 5 to 2 days $(P=0.004)$ and median hospital stay after surgery decreased from 5 to 3 days $(P=0.001)$. The complication rates did not show statistical differences between the two groups within the first 30 days postoperatively $(P=0.263)$. For the long-term complications, the incidence of abdomen bulge or incisional hernia in the CRT group was less than that in the standard group $(P<0.001)$.

Conclusion: The CRT technique, which combines both the advantages of retroperitoneal and transperitoneal approaches, is a more minimally invasive, simplified and effective way to perform the LNU.

Keywords: nephroureterectomy, laparoscopy, retroperitoneal, transperitoneal, single position

\section{Introduction}

Upper urinary tract urothelial carcinoma (UTUC) is a relatively rare urothelial neoplasm, accounting for about $5-10 \%$ of all urothelial carcinoma. ${ }^{1}$ However, its high recurrence rate and rapid progression seriously affect the prognosis of patients. Nephroureterectomy with bladder cuff excision is the current gold standard for the treatment of UTUC. ${ }^{1}$ Because of the low incidence of perioperative complications and the similar oncology control effect to open surgery, laparoscopic nephroureterectomy (LNU) is preferred in the majority of medical centers. ${ }^{2}$ 
Transperitoneal approach and retroperitoneal approach as two common methods in LNU, have their own advantages and disadvantages. Compared to retroperitoneal approach, it's easier to recognize anatomic landmarks during a transperitoneal approach, and it owns larger surgical space, which makes it easier to find the most appropriate angle for manipulating tissues. However, one of the accepted disadvantages is that the identification and mobilization of renal pedicle could be more difficult and time consuming. ${ }^{3}$ The standard surgical technique is now widely used in most of the centers. After laparoscopic resection of the kidney and proximal ureter segment with the patients placed in the lateral decubitus position, the distal ureter together with a cuff of bladder around the ureteric orifice are removed by open surgery when the patients' position must be changed to the supine position. Therefore, the operation time will be greatly prolonged due to the position change during operation, and open surgery will bring larger surgical trauma.

To solve the above problems, we created a new surgical technique which combined both the advantages of a retroperitoneal approach with a transperitoneal approach, and named it the CRT technique. The operation can be accomplished by adjusting the inclination of operating table, without changing the patients' position. The aims of the present study are to introduce our novel technique of CRT LNU, and to compare the early outcomes with the standard technique.

\section{Patients and Methods}

\section{Patients}

From January 2017 to December 2019, a total of 106 patients who underwent LRU at our department by one surgeon with extensive laparoscopic surgical experience were retrospectively analyzed in this study, of whom 50 patients underwent standard LNU from January to December 2017, while 56 patients underwent CRT LNU from January 2018 to December 2019. The indications for surgery included: 1) patients diagnosed with UTUC by preoperative biopsy or imaging; 2) renal or ureteral tuberculosis that cannot be treated conservatively; and 3) patients with duplication of kidney and ureter requiring surgical treatment. Preoperative evaluation consisted of standard history and physical exam, basic laboratory blood, cardiac and pulmonary work-up as indicated. All patients were examined by magnetic resonance (MRI) or enhanced computed tomography (CT) examination before operation and all UTUC patients had no metastatic disease. All patients had a normal renal function on the unaffected side.

All patients' characteristics, intraoperative, postoperative and follow-up parameters were recorded. Complications were analyzed according to the ClavienDindo classification. ${ }^{4}$

\section{Surgical Technique CRT Technique}

After general anesthesia, patients were placed in standard $90^{\circ}$ full flank position and secured to the table, then the table was rotated to maximize exposure of the kidney (Figure 1). The layout of the trocar is shown in Figure 2. A 2-cm incision was made at the center between the 12th rib and the erector spinae muscle (port B), the retroperitoneal space was entered by blunt finger dissection. After a retroperitoneal working space had been created using a balloon dissector, a 10-mm trocar was inserted at the middle axillary line $3 \mathrm{~cm}$ cephalad to the iliac crest (port A), and another 5-mm trocar was placed at the tip of the 11th rib (port C). After the pneumoperitoneum was created, laparoscopic camera and instruments were placed into port $\mathrm{A}, \mathrm{B}$ and $\mathrm{C}$, respectively. By dissecting along the psoas muscle, the posterior surface of the kidney was reflected medially. Then renal pedicle was identified with dissection of the renal artery and vein (Figure 3). After the renal vessels were isolated and clipped successively by Hem-o-lok clips, kidney was mobilized outside the perirenal fascia. The adrenal gland was spared in all cases unless involvement was suspected. The ureter was then mobilized caudally toward the level of iliac vessels. A surgical drain

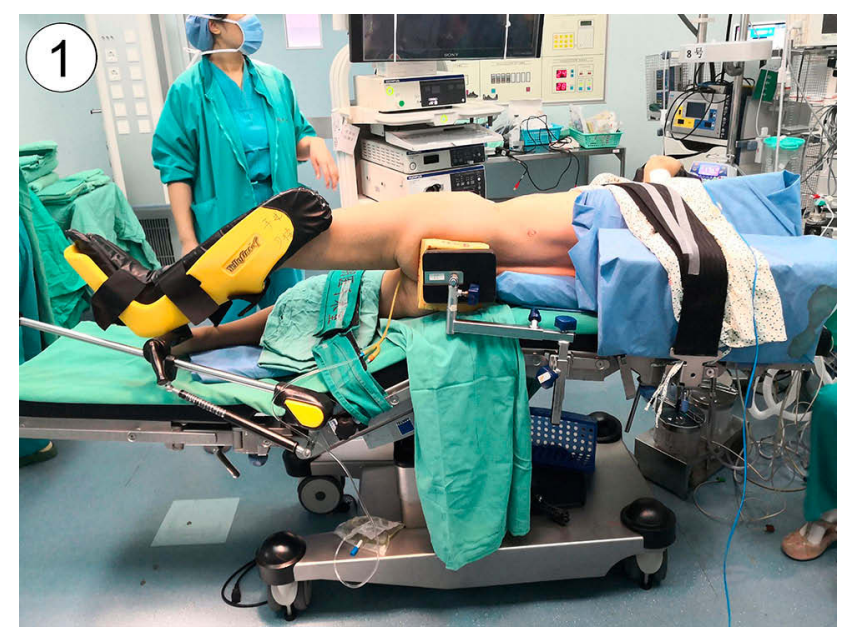

Figure I Patient position. The patient was placed in standard $90^{\circ}$ full flank position and secured to the table, then the table was rotated to maximize exposure of the kidney. 


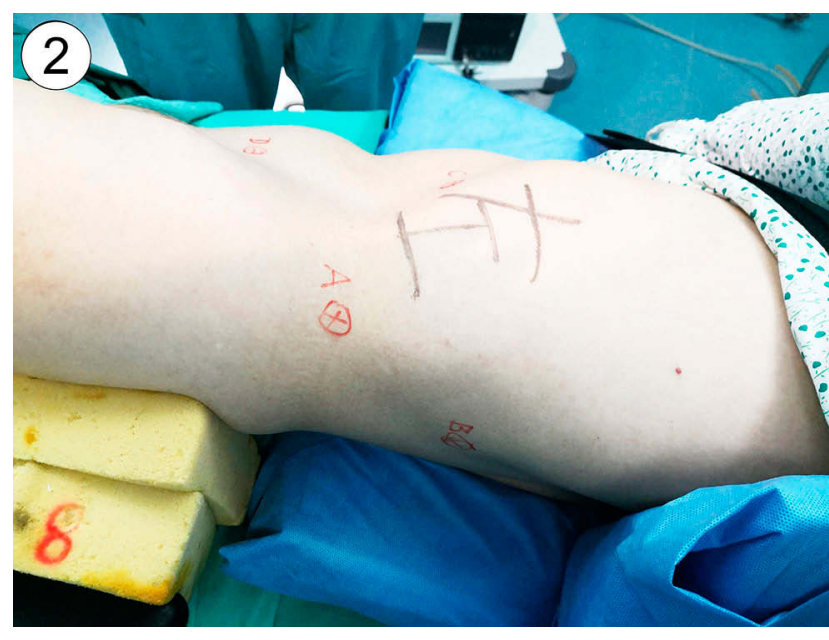

Figure 2 Trocar placement in retroperitoneal operation. A 2-cm incision was made at the center between the 12 th rib and the erector spinae muscle (port B), a 10-mm trocar was inserted at the middle axillary line $3 \mathrm{~cm}$ cephalad to the iliac crest (port A), and another 5-mm trocar was placed at the tip of the IIth rib (port C).

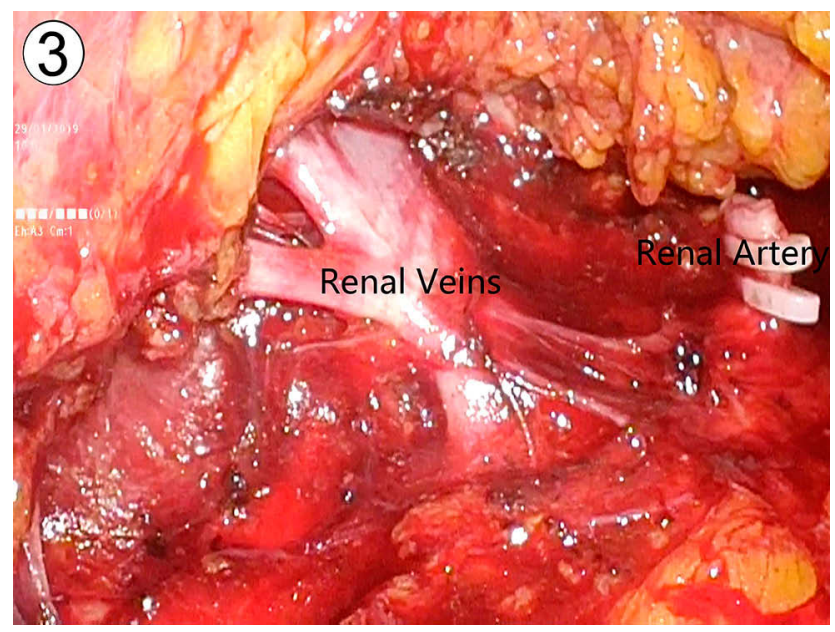

Figure 3 Dissection of renal pedicle through retroperitoneal approach. By dissecting the surrounding tissues of the kidney along the psoas muscle, the posterior surface of the kidney was reflected medially. Then renal pedicle was identified with dissection of the renal artery and vein.

was inserted through port $\mathrm{C}$ after the operation region was confirmed to have no active bleeding. Then, the patients were modulated to $30^{\circ}$ flank position by adjusting the table and another three trocars were inserted around the umbilicus (Figure 4). With a 10-mm trocar at the lower level of the umbilicus (port E), a 5-mm trocar at the midpoint of the line between the umbilicus and the anterior superior iliac spine (port D), and the last 12-mm trocar was placed $2 \mathrm{~cm}$ cranial to the pubic symphysis in the middle line (port F). The positions of all trocars would be adjusted according to actual individuals. The camera was then moved to caudal through port $\mathrm{E}$ and the useless trocar wounds were closed by surgical

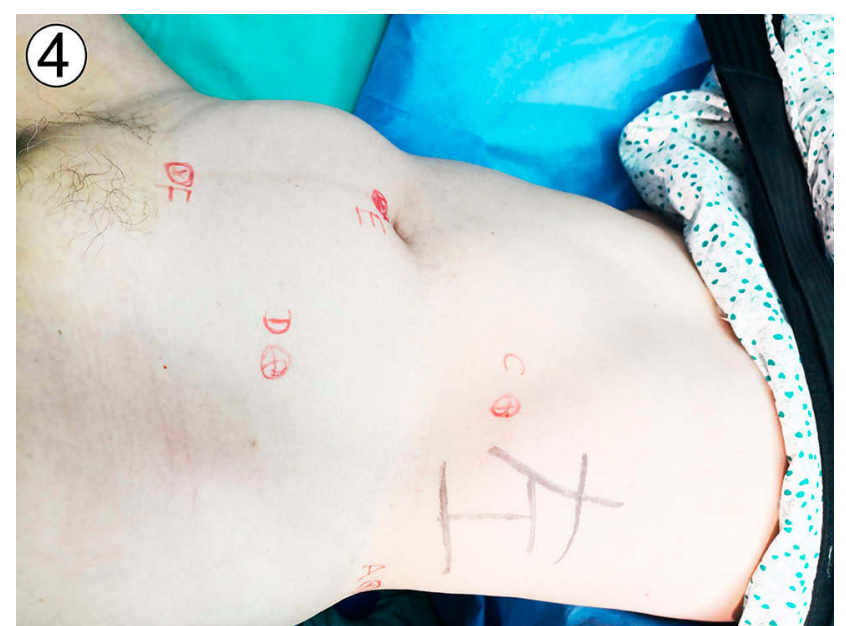

Figure 4 Trocar placement in transperitoneal operation. A 10-mm trocar at the lower level of the umbilicus (port E), a 5-mm trocar at the midpoint of the line between the umbilicus and the anterior superior iliac spine (port D), and the last 12-mm trocar was placed $2 \mathrm{~cm}$ cranial to the pubic symphysis in the middle line (port F).

assistant at the same time. The posterior peritoneum was dissected and the mobilized kidney was pulled into the abdominal cavity. The ureter was dissected caudally to the bladder wall and was excised with a cuff of bladder around the ureteric orifice. Specifically speaking, the surgeon dissociates the ureter to the intramural segment of the bladder entrance with a separation forceps, pulls the ureter opening and part of the bladder mucosa out of the bladder wall, and then cuts open the bladder wall, removes part of the bladder wall with sleeve resection of partial bladder at the ureterbladder opening, and sutures the whole bladder layer with 3-0 absorbable barbed thread (Figure 5). The entire nephroureterectomy specimen was put into a specimen bag and removed through an approximately $5-\mathrm{cm}$ abdominal median suprapubic incision.

\section{Standard Technique}

Following the laparoscopic radical nephrectomy, the patient was then placed in supine position and was reprepared and draped for the next open surgery. The distal ureter and bladder cuff were then dissected through a nearly $10-\mathrm{cm}$ lower-abdominal oblique incision, through which the specimen was removed. Lymph node dissection was not performed routinely for UTUC patients.

\section{Statistical Analysis}

All data were analyzed using SPSS version 24.0. Mean values with standard deviations were computed and reported for continuous data in normal distribution. Nonnormally distributed continuous data were described by median and 


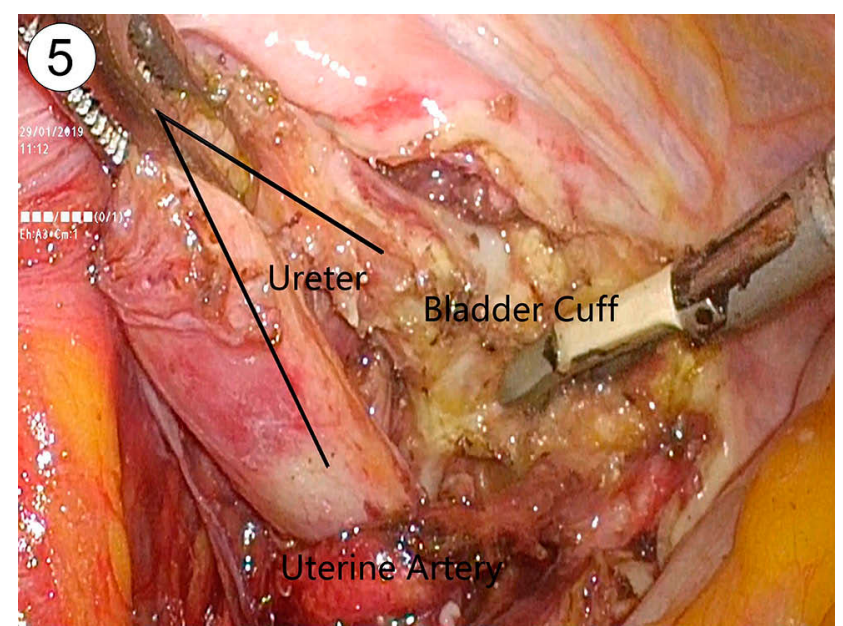

Figure 5 Dissection of distal ureter and bladder cuff through transperitoneal approach. The ureter was dissected caudally to the bladder wall and was excised with a cuff of bladder around the ureteric orifice.

interquartile range. An independent Student's $t$-test or MannWhitney $U$-test were used for comparison of normally distributed or nonnormally distributed continuous variables, respectively. Categorical variables were compared with Chisquare test. For all statistical tests, $P<0.05$ was considered to indicate a significant difference.

\section{Results}

Patients' characteristics are shown in Table 1. There was no significant difference between the two groups in age, sex distribution, BMI, disease category, location of UTUC, side distribution and American Society of Anesthesiologists (ASA) score.

All cases were completed successfully without conversion to open surgery. Perioperative parameters are shown in Table 2. Compared to standard group, patients in CRT group had shorter operative time $(P=0.001)$, less estimated blood loss (EBL) $(P<0.001)$, lower visual analogue scale (VAS) pain score $(P=0.020)$ and less scar $(P=0.013)$. The median time of surgical drain stay decreased from 5 to 2 days $(P=0.004)$ and median hospital stay after surgery decreased from 5 to 3 days $(P=0.001)$. The complication rates did not show a statistical difference between the two groups within the first 30 days postoperatively $(P=0.263)$. For the long-term complications, the incidence of abdomen bulge or incisional hernia in the CRT group was less than that in the standard group $(P<0.001)$. The mean operative time was 102.2 minutes for the CRT group and 214.5 minutes for the standard group. The median EBL was $40 \mathrm{~mL}$ for the CRT group and $100 \mathrm{~mL}$ for the standard group. The median VAS pain score was 2 for the CRT
Table I Characteristics of the Patients

\begin{tabular}{|c|c|c|c|}
\hline Variables & $\begin{array}{l}\text { CRT } \\
\text { Technique } \\
(n=56)\end{array}$ & $\begin{array}{l}\text { Standard } \\
\text { Technique }(n=50)\end{array}$ & $P$ \\
\hline $\begin{array}{l}\text { Age }(\text { mean } \pm S D) \text {, years } \\
\text { Male, } n(\%) \\
\text { BMl (mean } \pm S D) \text {, } \\
\mathrm{kg} / \mathrm{m}^{2}\end{array}$ & $\begin{array}{l}65.3 \pm 10.1 \\
30(54 \%) \\
23.4 \pm 2.5\end{array}$ & $\begin{array}{l}65.6 \pm 7.8 \\
30(60 \%) \\
22.4 \pm 2.4\end{array}$ & $\begin{array}{l}0.656 \\
0.505 \\
0.262\end{array}$ \\
\hline $\begin{array}{l}\text { Disease, } \mathrm{n}(\%) \\
\text { UTUC } \\
\text { Tuberculosis } \\
\text { Duplication of kidney } \\
\text { and ureter }\end{array}$ & $\begin{array}{l}53(95 \%) \\
1(2 \%) \\
2(3 \%)\end{array}$ & $\begin{array}{l}48(96 \%) \\
2(4 \%) \\
0\end{array}$ & 0.221 \\
\hline $\begin{array}{l}\text { Location of UTUC, } \\
\text { n (\%) } \\
\text { Renal pelvis } \\
\text { Upper middle ureter }\end{array}$ & $\begin{array}{l}29(55 \%) \\
24(45 \%)\end{array}$ & $\begin{array}{l}25(52 \%) \\
23(48 \%)\end{array}$ & 0.791 \\
\hline $\begin{array}{l}\text { Side, n (\%) } \\
\text { Left } \\
\text { Right }\end{array}$ & $\begin{array}{l}3 \mid(55 \%) \\
25(45 \%)\end{array}$ & $\begin{array}{l}23(46 \%) \\
27(54 \%)\end{array}$ & 0.336 \\
\hline $\begin{array}{l}\text { ASA score, } n \\
1-2 \\
3\end{array}$ & $\begin{array}{l}54 \\
2\end{array}$ & $\begin{array}{l}48 \\
2\end{array}$ & 1.000 \\
\hline
\end{tabular}

Abbreviations: CRT, combined retroperitoneal with transperitoneal; BMl, body mass index; UTUC, upper urinary tract urothelial carcinoma; ASA, American Society of Anesthesiologists.

group and 3 for the standard group and the median length of scar for the CRT group was $5.5 \mathrm{~cm}$, whereas for the standard group it was $11 \mathrm{~cm}$. The median time of drain duration decreased from 5 days in the standard group to 2 days in the CRT group and the median hospital stay after surgery decreased from 5 days in the standard group to 3 days in the CRT group. There was no statistical difference in other parameters (transfusion, ICU after surgery, time of intake of liquid diet, time of ambulation and time of urethral catheter).

The complication rates did not show statistical difference between the two groups within the first 30 days postoperatively $(P=0.263)$. In the CRT group, 9 patients $(16 \%)$ experienced at least one complication and all of them were minor complications (Grade 1-2). In the standard group, 12 patients (24\%) experienced at least one complication, and the majority of these complications were minor, except one patient simultaneously experienced deep vein thrombosis - a major complication (Grade 3-5) and underwent interventional treatment. The most common minor complications were fever, urinary infection and incision fat liquefaction. Notably, three patients experienced incision fat liquefaction in the 
Table 2 Perioperative Outcomes and Postoperative Complications

\begin{tabular}{|c|c|c|c|}
\hline Variables & $\begin{array}{l}\text { CRT } \\
\text { Technique } \\
(n=56)\end{array}$ & $\begin{array}{l}\text { Standard } \\
\text { Technique } \\
(n=50)\end{array}$ & $P$ \\
\hline $\begin{array}{l}\text { Operative time (mean } \pm S D) \text {, } \\
\text { minutes }\end{array}$ & $102.2 \pm 14.5$ & $214.5 \pm 23.3$ & 0.001 \\
\hline EBL (median [IQR]), mL & $40(30-50)$ & $100(80-112.5)$ & $<0.001$ \\
\hline Transfusion, n (\%) & 0 & I (2\%) & 0.472 \\
\hline ICU after surgery, n (\%) & $2(4 \%)$ & $4(8 \%)$ & 0.418 \\
\hline $\begin{array}{l}\text { VAS pain score after surgery } \\
\text { (median [IQR]), days }\end{array}$ & $2(I-2)$ & $3(2-4)$ & 0.020 \\
\hline $\begin{array}{l}\text { Time of intake of liquid diet } \\
\text { (mean } \pm S D \text { ), days }\end{array}$ & $1.1 \pm 0.3$ & $1.1 \pm 0.2$ & 0.306 \\
\hline $\begin{array}{l}\text { Time of ambulation (mean } \pm \\
\text { SD), days }\end{array}$ & $1.1 \pm 0.3$ & $1.1 \pm 0.4$ & 0.691 \\
\hline $\begin{array}{l}\text { Time of surgical drains } \\
\text { (median [IQR]), days }\end{array}$ & $2(2-2.75)$ & $5(4-6)$ & 0.004 \\
\hline $\begin{array}{l}\text { Catheterization time (mean } \\
\pm \text { SD), days }\end{array}$ & $1.3 \pm 0.5$ & $1.2 \pm 0.5$ & 0.614 \\
\hline $\begin{array}{l}\text { Hospital stay after surgery } \\
\text { (median [IQR]), days }\end{array}$ & $3(3-4)$ & $5(4-6)$ & 0.001 \\
\hline $\begin{array}{l}\text { Length of the scar (median } \\
{[\mathrm{IQR}), \mathrm{cm}}\end{array}$ & $5.5(5-6)$ & $11(10-12)$ & 0.013 \\
\hline $\begin{array}{l}\text { 30-day complication rates, } \\
\text { n (\%) }\end{array}$ & & & 0.263 \\
\hline None & $47(84 \%)$ & 37 (74\%) & \\
\hline Minor (I-II) & $9(16 \%)$ & $12(24 \%)$ & \\
\hline Major (III-V) & 0 & I (2\%) & \\
\hline $\begin{array}{l}\text { Hypogastric bulge or } \\
\text { incisional hernia, } n(\%)\end{array}$ & $4(7 \%)$ & $28(56 \%)$ & $<0.001$ \\
\hline
\end{tabular}

Abbreviations: CRT, combined retroperitoneal with transperitoneal; SD, standard deviation; EBL, estimated blood loss; IQR, interquartile range; ICU, intensive care unit; VAS, visual analogue scale.

standard group, whereas no patient experienced this complication in the CRT group. For long-term complications, 28 patients $(56 \%)$ in the standard group experienced hypogastric bulge or incisional hernia at about 5 10 months postoperatively, but only four patients in the CRT group experienced hypogastric bulge, and there was a statistical difference $(P<0.001)$. Except for two patients in the standard group who underwent herniorrhaphy, most of them did not require surgical treatment.

There was no significant difference in pathological outcomes between the two groups in UTUC patients (Table 3). The median follow-up time was 25 and 16 months for the standard and CRT groups, respectively. Four patients (8\%) in the standard group suffered local recurrence, which were all intravesical recurrences and two patients $(4 \%)$ suffered cancer metastasizing to lung and liver respectively. In the CRT group, one patient (2\%)
Table 3 Pathological and Oncological Outcomes

\begin{tabular}{|c|c|c|c|}
\hline Variables & $\begin{array}{l}\text { CRT } \\
\text { Technique } \\
(n=53)\end{array}$ & $\begin{array}{l}\text { Standard } \\
\text { Technique }(n=48)\end{array}$ & $P$ \\
\hline $\begin{array}{l}\text { Pathological } \\
\text { T stage, n (\%) } \\
\text { TI } \\
\text { T2 } \\
\text { T3 } \\
\text { T4 }\end{array}$ & $\begin{array}{l}7(13 \%) \\
36(68 \%) \\
10(19 \%) \\
0\end{array}$ & $\begin{array}{l}9(19 \%) \\
33(69 \%) \\
5(10 \%) \\
1(2 \%)\end{array}$ & 0.559 \\
\hline $\begin{array}{l}\text { Local } \\
\text { recurrence, } \\
\text { n (\%) } \\
\text { Metastasis, n (\%) }\end{array}$ & $\begin{array}{l}\text { I (2\%) } \\
\text { I (2\%) }\end{array}$ & $\begin{array}{l}4(8 \%) \\
2(4 \%)\end{array}$ & 0.603 \\
\hline
\end{tabular}

Abbreviation: CRT, combined retroperitoneal with transperitoneal.

suffered cancer metastasizing to lung, while one patient (2\%) experienced intravesical recurrence.

\section{Discussion}

The standard treatment for UTUC has traditionally consisted of open nephroureterectomy with excision of a bladder cuff. With technical improvements, LNU has been applied to patients extensively since the first case presented by Clayman et al. ${ }^{5}$ A series of studies have shown that LNU has similar oncologic outcomes compared to the open technique. ${ }^{6-8}$ However, compared with the open approach, LNU has many advantages eg, of decreasing blood loss, shortening hospitalization, reducing postoperative complications. ${ }^{9,10}$ The standard LNU, which is used in most centers, is divided into two steps. After retroperitoneal laparoscopic nephrectomy, the distal ureter with a cuff of bladder was excised through a lowerabdominal incision when the patient's position needed to be changed. Besides it is time consuming, involves large injury and more blood loss, the ureteric orifice has always been difficult to remove completely because of its deep position. ${ }^{11}$

With the development of minimally invasive technology, there are some minimally invasive techniques in nephroureterectomy, such as endoscopic, extravesical, or transvesical approaches or combination. Giovansili et al ${ }^{12}$ reported the technique for endoscopic management of distal ureter. The main technical points were that endoscopic resection through the bladder muscular wall was performed around the everted ureteral orifice, then the distal ureter was stripped and removed with a bladder cuff. Miyake et $\mathrm{al}^{13}$ reported transvesical laparoscopic excision 
of distal ureter in patients with UTUC. Simply stated, a total of three 5-mm trocars were inserted into the bladder. Circumscribing ureteral orifice and mobilizing ureter using fine 3-mm endoscopic scissors, and the defect of the bladder were sutured intravesically using 5-zero absorbable monofilament sutures. Nunez Bragayrac et $\mathrm{al}^{14}$ used a laparoendoscopic single port transvesical approach with pneumovesicum to create a working space to manage the distal ureter, followed by the nephrectomy and caudal dissection. This technique provided good control of the distal ureter, minimized the potential for tumor seeding. $\mathrm{Lim}^{15}$ made a comparison between laparoendoscopic Single-Site (LESS) nephroureterectomy and conventional multiport technique in the management of UTUC. They concluded that LESS-nephroureterectomy might result in greater intra-operative blood loss. Xylinas et al ${ }^{16}$ compared the results of RNU with three different approaches for the distal ureter. Overall, they did not find differences in non-bladder recurrence or survival between the endoscopic, extravesical, or transvesical approaches to the bladder cuff. However, the endoscopic approach had a higher rate of intravesical bladder cancer recurrence.

Our CRT technique, essentially an extravesical approach, which combines the advantages of both retroperitoneal (easy to mobilize and handle the renal pedicle) and transperitoneal (easy recognition of anatomic landmarks and large working space) approaches, has the following numerous advantages.

More extensive surgical indications: Besides UTUC and renal tuberculosis, duplication of kidney and ureter is very suitable for the CRT technique. As it is very close to the upper pole ureter and has a deep anatomical position, the lower pole moiety can be easily injured inadvertently in open surgery, but will be preserved well in laparoscopic surgery. Patients with the history of ipsilateral herniorrhaphy or renal transplantation may not be good candidates for a second hypogastric open surgery, but it will be managed successfully with CRT technique. In the current study, two patients with a history of ipsilateral herniorrhaphy or renal transplantation accepted CRT LNU respectively, and got good postoperative recovery.

Shorter operation time and less blood loss: Zargar et $\mathrm{al}^{17}$ reported a simplified approach of transperitoneal robot-assisted nephroureterectomy, which requiring no patient repositioning or robot redocking. Their mean operation time and median EBL was 300 minutes and $200 \mathrm{~mL}$. The reasons for less operation time of CRT technique are as follows: Firstly, It's more convenient and time saving to manage renal pedicle and nephrectomy through the retroperitoneal approach, which takes from 30 to 55 minutes generally; Secondly, The surgeon can choose the best angle to get the most sufficient exposure through moving the camera among the trocars; Thirdly, avoiding patients' repositioning, and less sterilization and draping during an operation can save a good amount of time. Fourthly, it is time saving for closing a smaller incision, which takes about 20 minutes in the CRT group.

More minimally invasive and enhanced recovery: Compared to standard technique, CRT technique has shorter incision length, is less painful, needs less time for surgical drains and shorter hospital stay after surgery. Three patients experienced incision fat liquefaction resulted from long operation and retractor time in the standard group, which needed much more time for wound caring.

Lower incidence of postoperative abdomen bulge or incisional hernia: In addition to the commonly recognized factors such as incision infection, old age, and high BMI, many studies have shown that the injury of muscle and neurovascular bundle (NVB) were significant risk factors for the occurrence of postoperative abdomen bulge or incisional hernia. ${ }^{18,19}$ Some studies have also reported that increased incision length, prolonged operation time and long-term using of retractors during surgery were statistically significant factors in the development of incisional hernia. ${ }^{20,21}$ In the present study, the incidence of postoperative abdomen bulge or incisional hernia in the CRT group was less than that in the standard group, the reasons may be related to the above factors.

Probably better oncological outcomes in the long run: Although no significant difference was detected in the disease-free survival (DFS) between the two groups, CRT technique has more appropriate angle and space to achieve complete resection of the distal ureter and bladder cuff. In the present study, there were four cases suffering local recurrence in the standard group, while there was no recurrence in the CRT group. With the time extending, there may be significant survival benefits in patients with the CRT technique.

Additionally, compared to the standard technique, which needs at least three to four staff, only two or three staff members are enough for the CRT technique.

There were several limitations in this study. First, it was a non-randomized retrospective study, and limitations may have existed in the study design account for selection bias. Second, the sample size was not large enough to make a convincing conclusion. Third, the follow-up period 
of our study was too short to obtain more significant differences between the two groups, especially in oncological outcomes. More large-sample and high-quality RCTs are needed to confirm these preliminary findings.

\section{Conclusions}

The CRT technique is a practical, simplified and more effective way in LNU, which combines both the advantages of retroperitoneal and transperitoneal approaches. It can be accomplished with the benefits of less operating time, less blood loss, faster recovery, more minimal invasion and possible better oncological outcomes. However, larger samples with longer follow-up are needed to confirm these preliminary findings.

\section{Abbreviations}

UTUC, upper urinary tract urothelial carcinoma; CRT, combined retroperitoneal with transperitoneal; LNU, laparoscopic nephroureterectomy; EBL, estimated blood loss; VAS, visual analogue scale; ASA, American Society of Anesthesiologists.

\section{Data Sharing Statement}

Data used and/or analyzed in the current research can be obtained from the corresponding author on reasonable request.

\section{Ethics Approval and Consent to Participate}

The study was approved by Research Ethics Committee of Beijing Chaoyang Hospital, Capital Medical University. All the patients in this study provided written informed consent. Each enrolled patient provided written informed consent. All information was handled following relevant ethical and legal standards.

\section{Acknowledgments}

The authors would like to thank all the 106 patients who agreed to participate in this study and completed the follow-up survey.

\section{Author Contributions}

Liming Song, Wenkuan Wang and Qinxin Zhao shared first authorship.

All authors contributed to data analysis, drafting or revising the article, gave final approval of the version to be published, and agree to be accountable for all aspects of the work.

\section{Funding}

There is no funding to report.

\section{Disclosure}

The authors report no conflicts of interest in this work.

\section{References}

1. Roupret M, Babjuk M, Comperat E, et al. European Association of Urology guidelines on upper urinary tract urothelial carcinoma: 2017 update. Eur Urol. 2018;73(1):111-122. doi:10.1016/j.eururo.2017.07.036

2. Liu F, Guo W, Zhou X, et al. Laparoscopic versus open nephroureterectomy for upper urinary tract urothelial carcinoma: a systematic review and meta-analysis. Medicine. 2018;97(35):11954-11961. doi:10.1097/MD.0000000000011954

3. Zhang C, Wang F, Shi X, et al. Direct lateral access to renal artery during transperitoneal laparoscopic partial nephrectomy: surgical technique and comparative outcomes. Urology. 2018;120:120-124. doi:10.1016/j.urology.2018.07.014

4. Mitropoulos D, Artibani W, Biyani CS, Bjerggaard Jensen J, Rouprêt M, Truss M. Validation of the clavien-dindo grading system in urology by the European association of urology guidelines ad hoc panel. Eur Urol Focus. 2018;4(4):608-613. doi:10.1016/j.euf.2017.02.014

5. Clayman RV, Kavoussi LR, Figenshau RS, Chandhoke PS, Albala DM. Laparoscopic nephroureterectomy: initial clinical case report. J Laparoendosc Surg. 1991;1(6):343-349. doi:10.1089/ lps.1991.1.343

6. Peyronnet B, Seisen T, Dominguez-Escrig JL, et al. Oncological outcomes of laparoscopic nephroureterectomy versus open radical nephroureterectomy for upper tract urothelial carcinoma: an European Association of Urology guidelines systematic review. Eur Urol Focus. 2019;5(2):205-223. doi:10.1016/j.euf.2017.10.003

7. Miyazaki J, Nishiyama H, Fujimoto H, et al. Laparoscopic versus open nephro- ureterectomy in muscle-invasive upper tract urothelial carcinoma: subanalysis of the Multi-Institutional National Database of the Japanese Urological Association. J Endourol. 2016;30 (5):520-525. doi:10.1089/end.2015.0757

8. Lee H, Kim HJ, Lee SE, Hong SK, Byun SS. Comparison of oncological and perioperative outcomes of open, laparoscopic, and robotic nephroureterectomy approaches in patients with non-metastatic upper-tract urothelial carcinoma. PLoS One. 2019;14(1):0210401-0210410.

9. Liu JY, Dai YB, Zhou FJ, et al. Laparoscopic versus open nephroureterectomy to treat localized and/or locally advanced upper tract urothelial carcinoma: oncological outcomes from a multicenter study. BMC Surg. 2017;17(1):8-18. doi:10.1186/s12893-016-0202-x

10. Seisen T, Peyronnet B, Dominguez-Escrig JL, et al. Oncologic outcomes of kidney-sparing surgery versus radical nephroureterectomy for upper tract urothelial carcinoma: a systematic review by the EAU non-muscle invasive bladder cancer guidelines panel. Eur Urol. 2016;70(6):1052-1068. doi:10.1016/j.eururo.2016.07.014

11. Miyake M, Tatsumi Y, Fujimoto K, et al. Changes in oncological outcomes after radical nephroureterectomy in patients with upper urinary tract urothelial carcinoma treated in the last two decades: a retrospective analysis based on a multicenter collaborative study. Jpn J Clin Oncol. 2016;46(12):1148-1155. doi:10.1093/jjco/hyw128

12. Giovansili B, Peyromaure M, Saïghi D, Dayma T, Zerbib M, Debré B. Stripping technique for endoscopic management of distal ureter during nephroureterectomy: experience of 32 procedures. Urology. 2004;64(3):448-452. doi:10.1016/j.urology.2004.04.080 
13. Miyake M, Nishimura N, Aoki K, et al. Initial experience of complete laparoscopic radical nephroureterectomy combined with transvesical laparoscopic excision of distal ureter in patients with upper urinary tract cancer. World J Surg Oncol. 2020;18(1):104-115. doi:10.1186/s12957-020-01872-1

14. Nunez Bragayrac LAN, Machuca V, Saenz E, et al. Transvesical aparoendoscopic single-site management of distal ureter during laparoscopic radical nephroureterectomy. J Endourol. 2014.

15. Lim SK, Shin TY, Kim KH, et al. Laparoendoscopic single-site (LESS) robot-assisted nephroureterectomy: comparison with conventional multiport technique in the management of upper urinary tract urothelial carcinoma. BJU Int. 2014;114(1):90-97. doi:10.1111/bju.12356

16. Xylinas E, Rink $M$, Cha E, et al. Impact of distal ureter management on oncologic outcomes following radical nephroureterectomy for upper tract urothelial carcinoma. Eur Urol. 2014;64:210-217. doi:10.1016/j.eururo.2012.04.052

17. Zargar H, Krishnan J, Autorino R, et al. Robotic nephroureterectomy: a simplified approach requiring no patient repositioning or robot redocking. Eur Urol. 2014;66(4):769-777. doi:10.1016/j.eururo.2014. 02.060
18. Inkiläinen A, Styrke J, Ljungberg B, Strigård K. Occurrence of abdominal bulging and hernia after open partial nephrectomy: a retrospective cohort study. Scand J Urol. 2018;52(1):54-58. doi:10.1080/21681805.2017.1376352

19. Osman T, Emam A, Farouk A, ElSaeed K, Tawfeek AM, AbuHalima A. Risk factors for the development of flank hernias and bulges following surgical flank approaches to the kidney in adults. Arab J Urol. 2018;16 (4):453-459. doi:10.1016/j.aju.2018.06.001

20. Itatsu K, Yokoyama Y, Sugawara G, et al. Incidence of and risk factors for incisional hernia after abdominal surgery. Br J Surg. 2014;101(11):1439-1447. doi:10.1002/bjs.9600

21. Marchand C, Renard Y, Avisse C, Palot JP, Larre S. Symptomatic lumbar incisional hernia after open nephrectomy: what are the risk factors? Prog Urol. 2016;26(5):304-309. doi:10.1016/j.purol.2016.02.011

\section{Publish your work in this journal}

Cancer Management and Research is an international, peer-reviewed open access journal focusing on cancer research and the optimal use of preventative and integrated treatment interventions to achieve improved outcomes, enhanced survival and quality of life for the cancer patient.
The manuscript management system is completely online and includes a very quick and fair peer-review system, which is all easy to use. Visit http://www.dovepress.com/testimonials.php to read real quotes from published authors. 